\title{
Women's Issues and Project Appraisal
}

\section{Ingrid Palmer}

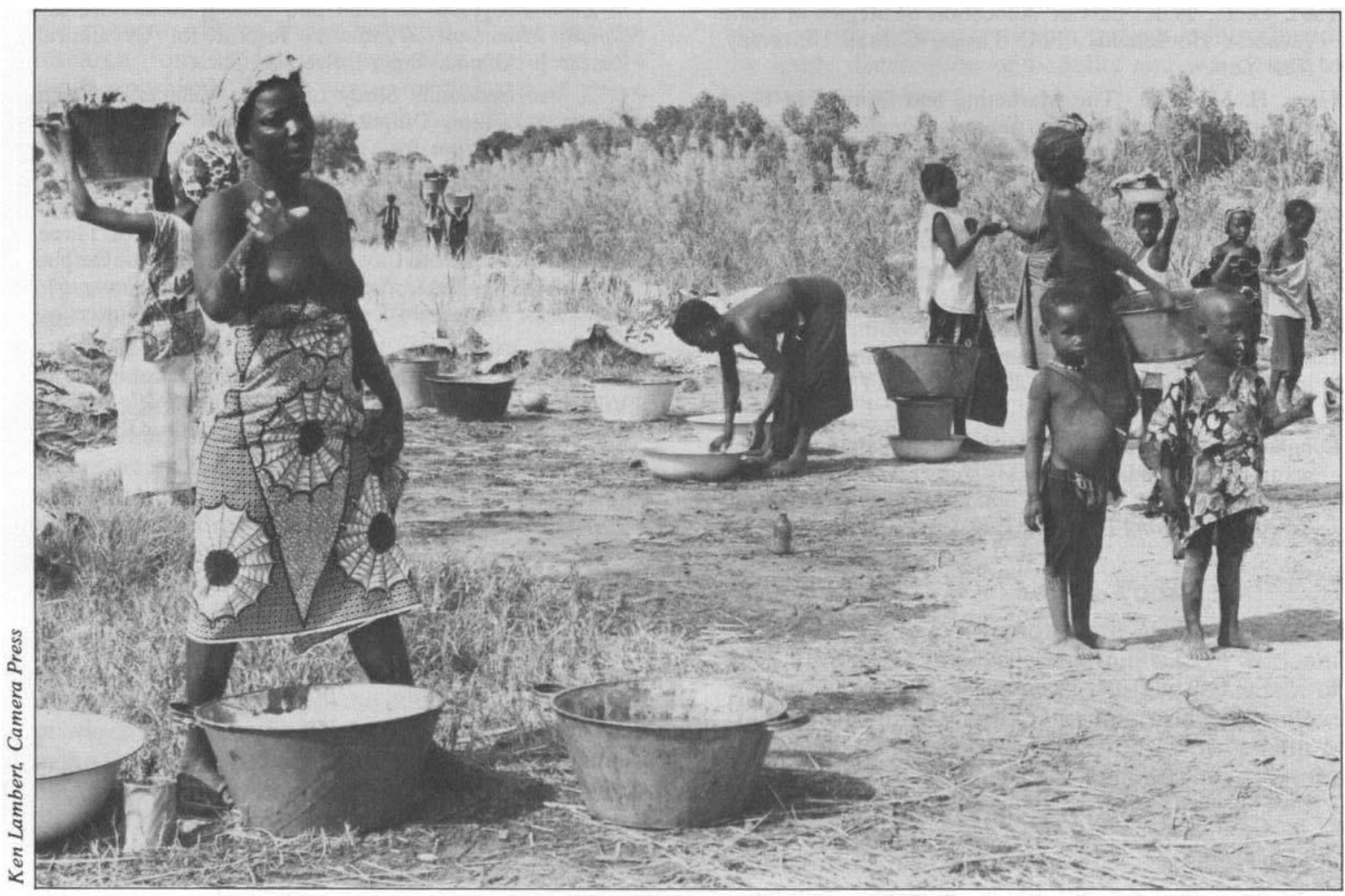

Women washing clothes in The Gambia Here the Moslem women are not secluded.

\section{Introduction}

Discussion of better methods of RRA is of particular importance to issues affecting women. Not only are women now widely believed to be amongst the more invisible and the 'poorest of the poor' who benefit dubiously from development projects, but the basic literature on wómen and development is not extensive, and what does exist is not widely read by (male) planners - with consequences for concepts and hypotheses to be tested. For these reasons greater emphasis needs to be laid on social stratification and social relations between the sexes and on their processes of change.

Invisibility, peripheral status, and poorer access to resources all raise questions relating to the methodology of field investigation, including the 'tarmac bias', time spent on certain groups, proxy indicators, and indepth study of otherwise hidden factors of terms of access. But the invisibility of women goes further-they have been rendered ideologically and theoretically as well as physically invisible. While their alleged shyness may contribute, this may have more to do with the impressions of all-male teams of investigators moving in high profile with an entourage of male officials and male village leaders. Certainly this writer has experienced no shyness on the part of village women.

The deficiencies, or absence, of an understanding of how women are affected by change is much more serious, as it questions what any investigating team is looking for. Much of the literature on women and development that does exist is of an academic nature,

Bulletin 1981, vol 12 no 4, Institute of Development Studies, Sussex 
undertaken to satisfy a readership looking for internal logic and analytical rigour. This is not so much wrong as inadequate in terms of policy-making, for it does not always help planners to rank the significance of gains and losses to women, to relate these to other project goals, or to present alternative designs and objectives. It describes what is, not what might have been. Moreover, as a result of long-term research it gives little indication of short-cuts in information gathering and the methodology that might be pursued for shorter evaluations. Finally, since the subject of women and development is still in an embryonic form, the existing literature is weak on certain areas, particularly project case study situations.

Some of the quantitative data required to fit together a picture of women's lives would be collected for other purposes: farm size, agrarian structure, yields, use of agricultural inputs and irrigated water, household produce and income, producer equipment and consumer durables, housing etc. These data may mean different things for men and women, but they are likely to be collected, and their interpretation for women is an exercise for a later stage. Of the remainder of the relevant quantitative data, women's time and labour allocation must take the lion's share, but they are impossible to collect during an RRA. There are other 'facts' to be collected, such as distance to health clinics, hospitals, domestic water points and sources of fuel, and use of these services and goods.

But the most important questions require qualitative responses: what are the present terms on which women work for their own households and others, on-farm and off-farm; what are women's responsibilities for providing their own families with basic essentials such as food; what are the specific implications for women of differences between the household (one budget and one cooking pot) and the family (perhaps several households farming the same land); what control over household resources and income do women have; what is the influence of men's roles in extra-household institutions for intra-household decision-making; what forms of women's associations exist; what constraints are on women to utilise health and family planning services, crêches, and other facilities? And how are all these issues likely to be affected by the proposed changes? How do the lives and livelihoods of women household-heads differ from those of other women? These issues are concerned with traditional behaviour patterns, social issues, and forms of personal relations, relations of intra-household exchange, as well as obstacles in the path of women improving their position (even when extra resources or services are offered them). While it is possible to go to the field with such a check-list, the details and the ranking of women's priority concerns are still questionable, and something less structured than a set questionnaire is needed to extract information.
The rapid appraisal of women's issues in project design is examined here in the order in which such appraisals might be conceived and implemented. This starts with the perceptions of the investigator (the 'ideology'), then the nature of information collection (the epistemological issues), aspects of methodology ('on the road ...') and finishes with the interpretation of information (the 'hermeneutics').

\section{Ideological Constraints and Theoretical Premises}

RRA may be undertaken with any of a number of purposes in mind: ex-ante feasibility or appraisal, monitoring, or ex-post evaluation. The general idea of a project will have been negotiated with governments long before an RRA team comes into existence. Even if it is a feasibility study, the pre-identification of the Project will have meant official identification of the problem the Project is designed to meet through officially stated purposes and objectives. After-theevent appraisal presumably examines the gains and losses, and for whom, as well as suggestions for improvements or alternative designs in similarly planned projects.

There has been much discussion of this delineation of RRA's functions in terms of ideological contraint. Is the implicit (real) purpose of RRA to justify the official objectives and implementation procedures, while the explicit purpose is to check the viability of the project? It is difficult to sympathise with those who see ideological constraints as a looming obstacle to effective RRA. If the brief reads like an outrageous act of prostitution of one's profession, why accept it? Certainly there are ideological problems (not least in the case of women's issues!) but to regard them as constraints is to ignore the challenging possibilities for informing, investigating, cautioning, condemning, and presenting alternatives. Above all, official generalised project objectives can be developed into more specific and beneficial sub-objectives, and pre-conceived structural designs and implementation procedures can be subverted or modified by argument and alternative options. The problem is really a personal one. How much of a fight is one prepared to put up, and what confidence has one in one's analytical skills to support such a fight?

That being said, what of the 'ideology'? Some advantage for women's issues can be gained from the subject being undeveloped. Planners do not yet see it as threatening as they may see a class analysis, and this gives RRA investigators a freer hand, since no ideology of what to seek may be laid down. Planners' ignorance can also be turned to advantage for the same reason, and there is scope for putting on paper information and ideas which offer the weight of first impressions. With so little formally established on women's issues, first returns to investigation can be enormous and 
impressive. With skill, formal preconceived project purposes and objectives can be broken down under subheadings whose power of argument planners may not yet have developed an immunity to.

But there can also be ideological obstacles, not least those posed by a little general knowledge of women's issues. First, there may be hostility to the study of impacts on women stemming from popular notions of western feminism undermining 'our unique culture'. This attitude may have been encouraged by some large multi-country in-depth comparative research on women's status by European universities. To some extent this source of apprehension can be assuaged by pointing out that it has been widely observed that women's traditional position weakens during the modernisation process but that careful project design might prevent this happening. Secondly, there may be an assumption that the sole purpose of this kind of RRA is to raise the productivity of women's labour in household-associated tasks in order that they can work more in commercialised production. An attempt may then be made to restrict RRA to investigate only this aspect. This is a case of using RRA only to confirm or justify a detail of the project already conceived in the plan. For instance, in the Women's Education Project in Upper Volta (McSweeney 1979) the goal was to enable women to acquire literacy and general information, and part of the means towards this was easing women's workloads through the introduction of technology. To support this, an early pre-evaluation study was made by French women sociologists who spent three weeks in the area confirming that women were very busy. This constituted a straightforward legitimisation of what had already been agreed between the Government, UNESCO and UNDP.

It would be desirable to discuss in general terms the value of systematised RRA investigation on women's issues from the standpoint of the efficacy of the project and the distribution of benefits. Far from presenting a tunnel vision view of the situation of women by making a shopping list of what women should have, it could be pointed out that with all change there are gains and losses, but that it is important to ensure that these fall equitably between groups and between sexes. This kind of theoretical base can be developed to extend to the different significance of a particular gain or loss to one group or one sex, so that it can be argued that some particular losses need to be avoided more than others because they constrain the individual, or generate further losses. Likewise, some gains may be more beneficial than others because they lead on to other gains by expanding the capability of people, or because they mitigate the effects of an unavoidable loss. Women, in particular, have multiple roles and responsibilities (many of which are related to the daily care of the young) which in a long-standing traditional situation have been supported by commen- surate access to resources and by checks and balances in the society. A project can change their access to resources, or the terms of their access, as well as the checks and balances, and if women sense that their ability to maintain the welfare of the family will be impaired by change they might practise a form of passive resistance to their new roles in production.

Therefore losses to women can be translated as losses to the economic side of the project insofar as their issues can be seen as a production item, rather than a consumption item, on the budget. One could argue that there is no obvious tradeoff between production and welfare planning concerns because through the work of women one stands or falls by the other.

This condensed view of the theoretical justification for including women's issues in an RRA can be tailored to the situation. Its tough economic and quantitative language should help to allay suspicions that an esoteric, or worse, a culturally offensive, element is being introduced. But sensitising arguments about what and whose gains and losses, and their significance, also shape an entrée into examining and presenting design and implementation alternatives to accommodate this new subject in a way which is seen by planners to strengthen the whole project.

\section{Epistemological Issues}

The crux of the epistemological debate on RRA is the balance between the empirical, hard questionnaire and the qualitative, holistic approach. Charges fly that the first gives ahistorical, snap shot material, is weak on relations and processes, accumulates excessive information which clogs computers and litters the floor of the cutting room, and stupefies the mind during the interpretation stage. The other side claims that facts is facts, that qualitative interpretation lacks scientific rigour and is prone to non-representativeness. It is assumed here (i) that nobody seriously supports the exclusive use of one approach or the other, and (ii) that RRA means only three to four weeks in the field.

One of the main difficulties for the women's component of RRA is that an analysis of likely or actual 'before' and 'after' situations is less obvious from a review of quantitative information in the case of women than men. This is because data on farming techniques, production and income allow conclusions on change to be made more easily for men than for women, whose lives are affected by much more than agricultural production and income (which are usually under the control of men in the first instance). Women's domestic lives are more time consuming and important than men's, and changes in intra-household decision-making are crucial to their access to resources with which to fulfil their nutrition, health care and mothering roles. Hence the women's component of RRA will be seeking answers to a very mixed bag of concerns with a strong 
emphasis on qualitative information.

Informationally, we should proceed as though we have a blank piece of blotting paper before us on which first enquiries will give rapidly increasing returns on the general conditions of women's lives and work and, in the case of an ex post evaluation, of changes in those conditions. Myths about women can sometimes be disposed of 'at a stroke'. For instance, on a very brief RRA on the Gezira Scheme in the Sudan this writer had a male official telling her that women did not work in the fields, while, looking over his shoulder, it was easy to see that the majority of cotton-pickers were women. Later on, male farmers said they sometimes used female family labour to 'help out', but during a two-hour interview alone with farmers' wives the women were emphatic that they worked longer in the fields than the men. Again, it was alleged that most seasonal migrant cotton-pickers were men, but an hour's talk with women in a migrant labour camp put paid to that notion too. (Their husbands were busy picking the cannabis crop up in the mountains.)

With such a comparatively unknown subject, it has to be assumed that baseline data and field investigation methodology are weak, and will remain so for some time. Until it is possible to develop systematised information-gathering systems, RRAs should be concerned with approximate, but pertinent and reliable, information rather than detailed and accurate, but dubiously relevant indicators (which can be used mischievously). For instance, starting from ignorance and an officially-conceived bias, the study of women in the Sudan described above might have concentrated on women's household-associated tasks and homebased industry and concluded that women had spare time. This positivist approach, founded on ignorance and prejudice, can be dangerous. Women's own words in response to open-ended and unstructured questions can speak louder than any amount of 'facts' built on a misconception. For instance, during an interview with farm women in the Sudan, a woman, who must have felt confident that the interviewer was seeking her ideas and opinions, stated bluntly that the women in the village wanted cotton fields of their own since they found themselves at present just working on their husbands' fields for nothing.

Given that a mass of baseline data is impossible, it becomes even more important for RRA investigators to review the literature-biases and all-that is available on that and similar situations. This alone should breed a healthy scepticism of any attempt at scientific rigour and value-free research, for the literature will reveal not so much what is stated but what is left unstated. But it may also hint at the existence of real problems which emphasis on a mass of facts can obscure. But if elegance of technique is impossible, what is to be sought or what hypothesis or conceptual insights are to be tested? Can an investigator carry any kind of check list of required data in her mind? And what of representativeness should be aimed for?

A quick and clean RRA must depend on a preceding conceptualisation of issues that are reasonably well grounded. If this conceptualisation cannot be grounded in facts it has to rely on theoretical assumptions deduced from other experiences or a reading of other situations. Like it or not, hunches have to be played-and conclusions have to be rumbled. After all, we are not out to satisfy $\mathrm{PhD}$ examiners but to complete voyages of discovery as successfully as possible. We should not fear that we are quite wrong on minor points, but we should fear that we are not approximately right on major ones, because a gleaning of the studies on the impact on women of agricultural development projects and the experience of a few past RRAs on the subject indicate just how wrong these projects have been for women on major points. (An important example of this has been described in Chambers and Moris eds 1973. See also Dey 1980.)

The commonality of women's experiences of different projects leads easily to a theoretical base for investigating these major points. According to the class of the woman, agricultural modernisation leads to an even heavier workload or redundancy in the wage market - a polarisation usually much more marked in the case of women than men. Gendertyping of agricultural tasks may alter with the introduction of mechanisation, providing the hypothesis that when the task is easier it passes to men. A shift from own-consumption to commercialised food production presents problems for women in the management of household nutrition. The progress of rural institutions awards men greater social visibility and entrepreneurial functions which can have implications for the intra-household distribution of authority. Land reform can disrupt traditional land inheritance practices. According to the class of the household, the use of child labour can increase or decrease, with implications for demographic behaviour and women's health. Commercialisation of production threatens the practice of kinship relations, gift exchange, and the support and protection mechanisms traditionally available to women. When men's and women's accounts are held separately (through separate sources of land and capital and different economic ventures) agricultural modernisation can create chaos in 'household' finances and financial responsibilities. New seasonal patterns of work-burdens and the incidence of polluted water can increase or diminish health problems whose resolution falls to women. Forestry preservation and/or resettlement of populations present new problems of fuel acquisition for cooking. And so on. To answer these questions both quantitative and qualitative information is required. 


\section{Facts and Indicators}

As already mentioned, much of the quantitative data collected for the other purposes of an RRA can be used to analyse women's situation: food sources, farm size, marketed produce, etc. In particular the indicators (proxy and others) to denote the class or peripheral status of a household can be as relevant to women as men. But caution is necessary even here. Jennie Dey's study (Dey 1980) of rice irrigation projects in The Gambia shows that because men's and women's accounts and assets are separate, the household lacks a full corporate existence, and that extrapolating from a man's income and social status to his wife's can give a very misleading picture. Polygamy also brings complications, since the work and life of first and last wives can be quite different, as can the work and life of women with or without sons.

Farm size and rent of a tenant farmer may be amongst the facts selected to determine the economic class and profitability of a farming family. But it is a widespread practice that included in the 'rent' may be the tenant's wife's unremunerated domestic work in the home of the landowner. An economist may see this as irrelevant to his analysis since it is not part of the tenant household's cash transactions, and with scarity of land and wage employment, the virtual zero opportunity cost of the wife's domestic labour makes this labour 'free'. However, from the point of view of child care, nutritional standards, water and fuel collection, vegetable gardening and so on, as well as the wife's workload, her work in another's home has a real cost. Thus even if a cross-analysis of indicators has provided a reasonable basis for identifying a woman's 'class' through her husband's, it has to be borne in mind that being a member of that class can mean different things for women and men.

Some popularly promoted proxy variables of class are very useful to a study of women's conditions. These include quality of roofs and geographical location in the village. Distance from a domestic water point could be added. The common list of consumer durable acquisitions is useful, but should be handled discriminatingly. Not only should the presence or absence of a calor gas cooker (or the general condition of the 'kitchen') be noted alongside bicycles, radios and watches, but the ranking of dates of acquisition of different durables can reveal the decision-making process behind the acquisition of these goods. The dates of acquisition of agricultural machines and implements might likewise be interposed. The use of dates can ease the limitations of a snap-shot quantitative picture by introducing an element of time span and revealing the flow of surplus accumulation.

However, the use of proxy variables for interpretive meaning can change over time. For instance, in South Korea, the Saemul Movement has improved housing (particularly roofs) by extra-household decision-making, so better housing may no longer be a reliable indicator of income or nutritional status. Likewise, an RRA in South Korea revealed an abundance of calor gas cookers, but almost all were unused in 1980 because of the high price of calor gas, forcing women to revert to wood fuel at a time when wood was becoming difficult to collect.

Health indicators are difficult from both the conceptual and data collection angles. The existence of hospital beds, health clinics, nurses and family planning centres tell us nothing of their use. Women's life expectancy rates can highlight the existence of serious poverty and even the class status of the household-since women are the 'poorest of the poor'-but other than on a national or regional aggregate basis they are difficult to obtain. Interviewing medical workers on various aspects of health issues, particularly seasonal factors, is much more useful.

There is a particular problem in the case of a women's component of RRA in deciding what is the cut-off point of the range of indicators to be settled on and the depth of enquiry on individual indicators. Even using a hard questionnaire technique the relevance of subindicators (breaking down an indicator) or the need to re-define an indicator may emerge as the interviews proceed. Judgements may also have to be made on the tradeoff of time spent in collecting information on various indicators, if some are found to be easier to collect or some can stand in for others. Thus there should be recognition of flexibility and an evolutionary process in the collection procedure of even hard quantitative data.

\section{Qualitative Information, Social Structures and Holistic Approaches}

Most of the RRA information on women's issues will be non-quantitative and obtained from asking the women themselves for descriptions and explanations. Their very mixed work portfolio and their coverage of both commoditised and non-commoditised output of goods and services suggest questions about the necessity for them to juggle tasks (rather than the fine allocation of time as would be measured by a quantitative longterm study), on the degree of freedom they have for organising themselves in their own way, on the enabling and consumption resources available for them, and finally, on their view of their lives and desirable or possible improvements. At the least this kind of information should suggest whether a proposed or past project is wildly wrong-information not to be sniffed at in the case of women's issues. Social structures and relationships are dependent on access to resources to fulfil the various functions they entail, and derived 
benefits, and since women are at the bottom of the (adult) social hierarchy, the structures and relationships affecting them will be different from those affecting men. Because of the difficulties of navigating this comparatively uncharted territory, it is better to clarify the structures and relationships which RRA wishes to know about, and then concentrate on devising different ways of posing selected questions to elicit this information. If conclusions are to be 'gleaned' or even 'rumbled', then weaving the same question into an interview in different forms might be the best way of getting informative answers. Patterns emerge from cumulative responses to what is essentially the same question posed in different ways, and these patterns help predictability. The phrasing of the questions, of course, can be improved upon in later interviews. It is difficult to know what short cuts can be made in this process until more experience is gained. Contrary to what positivist RRA investigators might suppose, this usually leads to more accurate approximations of the truth.

It is very important to ensure that issues which affect women specifically are asked of them and not of others. (A point which is emphasised in the next section on field-work methods.) For instance, in a brief piece of rural tourism in Sri Lanka, male farmers stated that now that they had tractors it was the men who collected the fuel. Closer questioning of the women revealed that the women still spent two halfdays a week collecting fuel, by walking for half an hour to the forest, cutting the fuel, leaving it in bundles for the men to place on the tractors, and walking back. Again, on a famine patrol in the New Guinea highlands, the men stated that the new sweet potato crop would take another nine to thirteen months to mature, but the women (who cultivated the crop) assured the patrol it would take only another four to five months. The sexes' interests were different: the men wished the famine rations to continue as they were a means of exercising local patronage and power, ' while the women saw the next sweet potato harvest as the point when their own role in society could be resumed.

On the question of benefits gained from a development project it is essential to obtain the separate views of the sexes. In the Sri Lanka case a male farmer expressed enthusiasm for the project, saying that his life had improved as his income had increased. Thirty yards away, on the other side of the field, this man's wife said that she did not like the project as it had made her life 'more difficult'. It is clear that analysis at the 'household' level is grossly inadequate.

The use of hypotheses on what is likely to have happened in social relations and decision-making practices as the result of a project can be useful as a means of crystallising questions and sub-questions. But there needs to be a readiness to modify hypotheses during investigation. This is most likely to occur following elucidation of the women's class; for instance, assumptions of changes in work may be correct for farming women but not for landless women. Again, when it becomes apparent that some women have managed to overcome or mitigate constraints, further on-the-spot questioning is necessary. An example of this comes from Sri Lanka. Agricultural economists on an RRA were talking loosely, on the long ride to the area, of the 'family' and the 'household', and how second and third generation women on the irrigation scheme had an easier life than first generation women because land scarcity had led to two, or even three, generations in a family farming the same land, so that mothers had other adult women to help with domestic tasks. It took just two hours in a village to learn that some multi-generation families farming the same land lived under the same roof and ate from the same cooking pot, while others were dispersed under two or more roofs and ate from separate cooking pots.

The non-positivist approach relies on the capacity of the appraiser to gauge the relative significance of pieces of information. But she is helped by listening to women's answers to open-ended questions, since the women are likely to indicate their priorities. A little prodding during a long imterview should encourage respondents to explain their greatest difficulties and the obstacles facing them in resolving problems.

But the problems of this approach to RRA on women's issues should not be underestimated. The identification of key social relationships and descriptions adequate for interpretation will be difficult. Models for predicting their dynamic evolution under change have not been developed. There can be no question of devising optimal RRA methods for some years, but the development of sub-systems as based on the overall epistemology of RRA and leading to a holistic picture might be considered in the interim. Granted all the dangers of compartmentalising women's complex lives, there is a case for building up an epistemology of women's roles im agriculture and likely changes therein, women's roles in producing, appropriating or purchasing the household's food requirements and likely changes therein, and women's domestic tasks of child-care, hygiene, cooking, etc. Putting these sub-systems together, more stressful or easier accommodations of conflicts can be surmised or guessed.

\section{On the Road and in the Field}

The tarmac bias is at least as important for specifically women's issues as for men's. When a government has attempted to improve the lot of the rural poor with better housing, roads, wells, cemented washing points, it usually begins with villages closer to main roads, and even houses in greatest visibility. The differences in 
these facilities between villages can be as great as, or greater than those within a village. While governmentsubsidised improvements may not be good indicators of the prosperity of households, the facilities themselves can make a great difference to work methods. But distances from tarmac roads also mean distances from schools, transport, and most importantly for women, from hospitals, health clinics, and maternal and child health centres. Midwives might be willing to walk or cycle to villages in close proximity, just as husbands might be willing to go out and fetch a midwife who is only three kilometres away.

Rocketing around in a Land Rover over rough roads for hours on end can be tiring and dispiriting, but there is no other way to reach the furthest and usually poorest villages. More time must be set aside for reaching these villages.

Likewise, within a village the poorest households may be on the periphery, furthest from canals, wells and cemented washing points. If they are far from water sources, kitchen gardens may be absent. Distance from the centre of the village may have the effect of isolating women from a village network of women's information on the time of health visits or family planning demonstrations. Electricity might not have reached all the houses. Often only a thorough tramping through the village reveals their existence. Again, time must be allowed for reaching the women in these households.

On a very quick RRA there may be no opportunity to exercise sampling techniques. On an RRA in nine villages in South Korea, allowing about $2 \frac{1}{2}$ hours in each village this writer aimed to set up interviewing points in at least two homes or places in the village. If it was obvious that the first location, perhaps at a washing point, gathered in a group of women over a class spectrum she moved amongst the women.

It is difficult to judge beforehand how to allocate time between individual and group interviews. Much depends on the culture and the degree of class conflict. In one Korean village a leading woman proved a poor interviewee and gave what seemed to be formal statistics and much qualitative bias. In another, the head of a Mother's Club asked this writer what she wanted to see and led her to some very poor women. It was clear that the poor women trusted this woman leader who helped to organise abortions for them, lent them money, and wrote official letters for them. While with her, a man approached and asked what he should do for his wife as she was 13 weeks pregnant and had attempted a self-induced abortion in vain.

One rule to follow is to cut short a seemingly useless interview and to move onto another as quickly as possible.
For a larger RRA, both individual and group interviews are desirable. In the ex-post evaluation for the Upper Volta Women's Education Project this was done with all-women groups and later mixed sex groups. The latter was extremely useful in showing the differences in men's attitudes between Project villages and control villages. In all-women groups, there seems to be more confidence in responses, and it has been the experience of this writer that in a variety of cultures (Korean, Sri Lanken, Sudanese and New Guinean), individual women in groups quickly start replying loudly, butting in on each other, arguing, raising their voices and being emphatic in their answers.

The seasonal timing of RRA visits can determine the responses to questions on work, water collection, health, and so on, unless care is taken during interviews to ask about other times of the year. Longer time spans and dependence on powers of recall are needed for questioning on 'before' and 'after' situations. The age profile of interviewees can be important as well, for not only is it useful to obtain views of women at different stages of the family life cycle, but opinions of grandmothers on differences between their past lives and the lives of younger women can be significant. Comparisons of the lot of first, second and third generation mothers on an irrigation project can be extremely illuminating if the general thrust of change on women's lives is sought.

It is often said that women make shy interviewees. In the experience of this writer this is emphatically not so when no men are present. While men might be able to establish rapport with village women over long periods of residential research, such as for PhDs, in the case RRAs women enumerators and interpreters must be used. In Korea when a female interpreter was substituted for a male interpreter things warmed up immediately. Women are generally more forthcoming than men with information. In some respects they belong to a sub-economy and a sub-society and have weaker vested interests in the village power game and systems of patronage. A private, informal discussion with them assumes procedures quite different from the discussions of male farmers facing the larger entourage of male visitors (usually including the welldressed ubiqitous local officials). Male farmers have to answer questions in front of local officials on whom they depend for patronage or services, and sometimes give answers appropriate to that situation. In Korea, male members of the RRA team were obviously getting wrong answers to irrigated water distribution issues and asked this writer to pose the same questions to the women. It was later confirmed that the women gave the correct answers.

Of course, questions about conditions of life, constraints on doing things and use of facilities are not so loaded with political content as questions of agricultural 
techniques, yields and services, but there is a striking opportunity for intimacy amongst a group of women who all understood the relative powerlessness of their positions-interviewer and interviewees alike. Inspecting babies, touching each other, exchanging information on family planning uses, all establish a rapport which men cannot begin to emulate. Even men respond to the female rural tourist. In one Sri Lankan village, with no common language except this writer holding the hand of his wife, a man pulled her into his house, dug around in a chest of drawers, pulled out a certificate of his sterilisation, and showed it with great pride. Had an interpreter been present some valuable intimate information on family planning decision-making would have been possible. The instance of a man enquiring on his pregnant wife's behalf in Korea has already been mentioned. In the Sudan, some family women replied to questions on female circumcision in a most uninhibited demonstrative manner.

There is, of course, a proper order for asking questions, which leaves difficult or intimate questions at the end of an interview. But this is sound practice and a question of common sense.

An RRA on women's issues would not be complete without a visit to the local health centre to ask about the incidence of illnesses (particularly infant dysentry), use of medical services, seasonality of medical problems, and changes in recent years. These are technical questions which village women may not be able to answer so well, and medical workers can provide a higher degree of representativeness of problems.

RRA on women's issues cannot be systematised for a number of years, but as a means of informing and educating planners and of minimising avoidable mistakes, it has enormous potential. It is said that planners wish to 'integrate women in development', but women are already integrated in agricultural production, sometimes more so than men, and are the focal point of the delivery of basic needs to the family. What is important is to understand that in some ways they are in the position of social and political minors, and that the process of modernisation has had the effect of increasing their relative powerlessness without diminishing their work and other responsibilities. Listening to women themselves will provide inspiration for reversing this process.

\section{The Hermeneutic Part of RRA}

Each successive RRA will add to the methodology of interpreting quantitative and qualitative information, but it has to be accepted that for the next five to ten years it will be a somewhat hit-and-miss procedure. The main goal should be that the major mistakes in project planning of the past must be avoided and that women should be, at least, guaranteed (a) avoidance of new excessive workloads and (b) inputs of access to resources commensurate with their responsibilities.

The interpretation of information in a particular RRA must depend on its purposes: ex-ante, ex-post, or monitoring project evaluations. But for all these purposes a great deal of new information will be gathered, far in excess of the data base assumed by the brief. There will be opportunities to add to theoretical conceptions, overturn assumptions made in the indentification process. And with such a new subject, liberties can be taken to point out misconceptions, to warn against project designs, and to offer alternative design options. The role of women in agriculture can be seen as a 'lead issue' so that what is expected of a new agricultural techonology can be revealed as imposing $\mathrm{A}, \mathrm{B}$ and $\mathrm{C}$ on women and as presenting problems $\mathrm{X}, \mathrm{Y}$ and $\mathrm{Z}$ for other aspects of their lives. In this part of the analysis, the qualitative information gained has to be depended on in order to see the dynamic in the quantitative facts which on their own merely describe the status quo.

What is 'good' in a project should be conceptualised in terms of gains and losses, their interrelationships and their outcome on balance. There will always be losses during change, but the notion of minimising avoidable suffering can be invoked, as can the notion of maximising avoidable gains. It might be seen that some gains are dependent on some losses, that particular gains should be aimed at or particular losses avoided as they release second generation effects.

During the report stage, it is important that the RRA investigator on women's issues compares notes and liaises closely with the rest of the RRA team. Her information can feed back into their brief and may overturn some of the assumptions and biases they have not questioned. There may also be contradictions in the respective data that have been collected which must be resolved by close discussion. Above all, it is desirable that the component of women's issues be interpreted in the overall report and not compartmentalised in such a manner that it can be dismissed as a marginal or esoteric subject.

\section{References}

Dey, J. M., 1980, 'Women and Rice in The Gambia: the impact of irrigated rice development projects on the farming system', $\mathrm{PhD}$ thesis, University of Reading

McSweeney, Brenda, 1979, 'The Negative Impact of Development on Women Reconsidered: a Study of the Women's Education Project in Upper Volta', PhD thesis, Fletcher School of Law and Diplomacy

Chambers, R. and J. Moris (eds), 1973, Mwea: An Integrated Rice Settlement Scheme in Kenya, Weltforum Verlag, Munich 